\title{
Gallbladder ulcer erosion into the cystic artery: a rare cause of upper gastro-intestinal bleeding Case report
}

\author{
Offir Ben-Ishay*, Mouad Farraj, Pavel Shmulevsky, Benjamin Person, Yoram Shimon Kluger
}

\begin{abstract}
Intra luminal gallbladder bleeding is a rare cause of hemobilia that results in upper gastro-intestinal bleeding. In this case report we present a patient who presented with melena and eventually was diagnosed as bleeding from an ulcer in the gallbladder which was induced by gallstones and eroded into the cystic artery. Surgery revealed perforation of gallbladder which was the result of a pressure sore induced by a second gallstone.
\end{abstract}

\section{Introduction}

Bleeding into the biliary tree or Hemobilia is a rare cause for upper gastro-intestinal bleeding that was first described by Francis Glison in 1654 [1]. Most commonly hemobilia is the result of trauma or investigatory interventions but inflammation, vascular malformation, malignancy and coagulopathy were also described as potential causes of hemobilia. A gallbladder ulcer eroding into the cystic artery is very rare, and only a handful of case reports of this entity are reported in the literature. When diagnosed, angioembolization followed by cholecystectomy is the recommended treatment.

We present a patient who was admitted due to melena and eventually was diagnosed as having hemobilia resulting from bleeding into the lumen of the gallbladder due to erosion of the cystic artery by gallstones.

\section{Case Description}

A 68 year old man, with past history of ischemic heart disease, hypertension, hypercholesterolemia, fatty liver and gallstones presented to the Emergency Department complaining of colicky pain in the right upper abdominal quadrant and black tarry stools. On admission, the patient was hemodynamically stable with a heart rate of 80 beats per minute, a blood pressure of $140 / 80 \mathrm{mmHg}$, and Oxygen saturation of $98 \%$. Physical examination revealed jaundice and marked tenderness in the right upper abdominal quadrant. Digital rectal examination

\footnotetext{
* Correspondence: o_ben-ishay@Rambam.health.gov.il Department of General Surgery B, Rambam Health Care Campus, Haifa, Israel
}

revealed melena with no fresh blood. Laboratory results showed leukocytosis, slight elevation in total bilirubin $(3.25 \mathrm{mg} / \mathrm{dl})$, elevated gamma glutamyl transpeptidase (738 U/l) and alkaline phosphatase-B (391 U/l). Ultrasonography showed a gallbladder with features compatible with cholecystitis containing large stones. No dilatation of the intra and extra-hepatic bile ducts was noted. Upper endoscopy with a side view endoscope revealed blood coming through the duodenal papilla with no evident papillary pathology. Angiographic computerized tomography (Figure 1) revealed active bleeding into the lumen of the gallbladder that contained two large stones. Emergency surgery was elected rather than

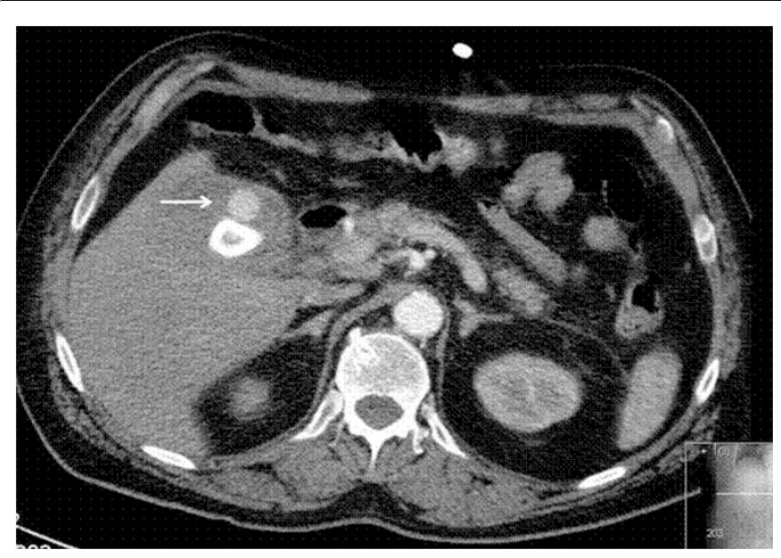

Figure 1 Computerized Tomography showing active bleeding into the lumen of the gallbladder. 


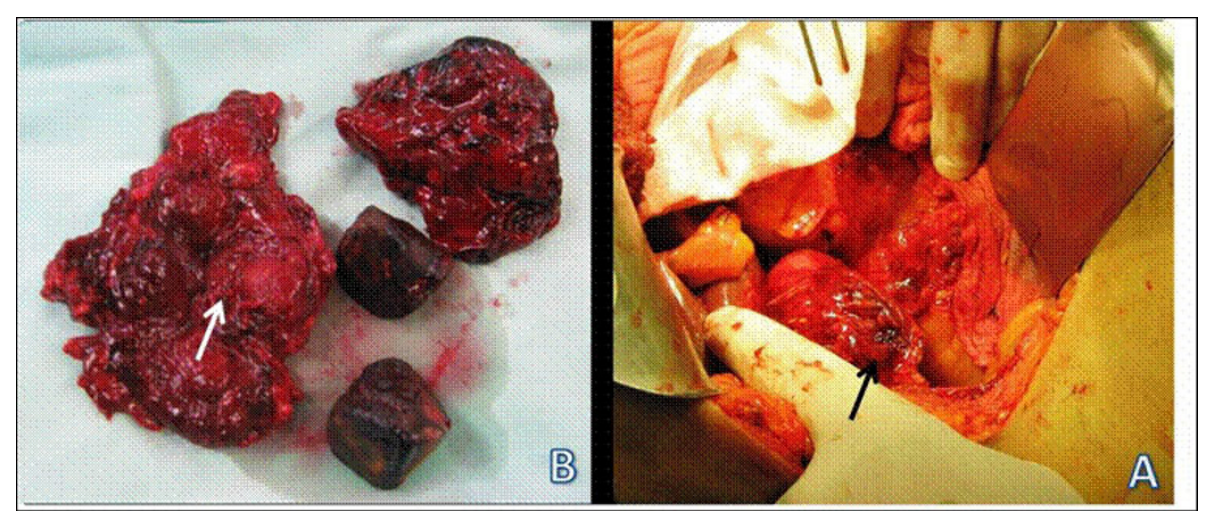

Figure 2 A - Perforation of the gallbladder. B - the respective ulcer leading to free perforation and the causing gallstones.

angioembolization due to clinical and laboratory indices of acute cholecystitis.

An open surgical exploration revealed the following findings: the omentum was adherent to the gallbladder and liver. The adjacent tissues were edematous and inflamed. The free wall of the gallbladder near the Hartmann's Pouch was perforated with blood clots obstructing the defect (Figure 2). Dissection of the gallbladder resulted in rupture of the gallbladder wall with massive bleeding from within its lumen. Control of the bleeding was achieved by a 5 minutes Pringle's maneuver that allowed the full dissection and removal of the gallbladder. Two large drains were left in the bed of the gallbladder and post operatively some bilious discharge was seen. The minor bile leak was managed conservatively with observation only and the discharge spontaneously ceased after several days.

On exploration of the resected specimen, two large gallstones were found, and a $0.5 \mathrm{~cm}$ ulcer was observed in the gallbladder wall.

Histopathologic examination was consistent with acute and chronic cholecystitis involving all layers of the organ that resulted in the formation of an ulcer with rupture of a pseudoaneurysm of the cystic artery.

The patient was discharged on the fourteenth post operative day; the drains were removed during the first postoperative outpatient clinic encounter and patient recovered uneventfully.

\section{Discussion and Conclusions}

Spontaneous intra-cholecystic bleeding is a rare occurrence which was described in patients with gallstones [2] gallbladder malignancy [3] and patients receiving anticoagulant therapy [4]. Bleeding as a result of an ulcer eroding into an otherwise normal cystic artery or pseudoaneurysm of the cystic artery is rare [5-7]. When diagnosed, angioembolization of the bleeding cystic artery was suggested as the treatment of choice for bleeding control. In this report, we presented a patient who had large gallstones leading to the formation of a decubitus ulcer that eroded into the cystic artery with the formation of a pseudoaneurysm that ruptured and bled into the lumen of the gallbladder causing hemobilia with subsequent overt upper gastro-intestinal hemorrhage. A large gallbladder peroration, also presumed to be a result of a second decubitus ulcer was revealed during the surgical exploration.

Upper gastro-intestinal bleeding should be addressed promptly. If hemobilia is diagnosed and large stones in the gallbladder are detected, bleeding from a gallbladder ulcer should be ruled out. If angioembolization is elected, this should be followed immediately with surgery as the clinical set-up of bleeding due to gallstones might suggest a more complicated gallbladder disease than previously suspected.

\section{Decleration of competing interests}

The authors declare that they have no competing interests.

\section{Patient Consent}

Written informed consent was obtained from the patient for publication of this case report and accompanying images. A copy of the written consent is available for review by the editor in chief of this journal.

\section{Authors' contributions}

$\mathrm{OBI}$ - Study concept and design and drafted the manuscript, MF - Operating Surgeon, PS - Operating Surgeon, BP - Critical review study concept and design, YK - Critical review study concept and design. All authors read and approved the final manuscript

Received: 9 January 2010 Accepted: 12 March 2010 Published: 12 March 2010 


\section{References}

1. Glisson Francis: From Anatomia hepatis (the Anatomy of the liver), 1654

(Cambridge Wellcome texts and documents). Cambridge: Wellcome Unit for the History of Medicine 1993.

2. Contini S, Uccelli M, Sassatelli R, Pinna F, Corradi D: Gallbladder ulcer eroding the cystic artery: a rare cause of hemobilia. Am J Surg 2009, 198(2):e17-9.

3. Ku J, DeLaRosa J, Kang J, Hoyt D, Coimbra R: Acute cholecystitis with a hemocholecyst, as an unusual presentation of gallbladder cancer: report of a case. Surg Today 2004, 34:973-976.

4. Karatepe O, Tukenmez M, Adas G, et al: Cholecystitis caused by hemocholecyst: an unusual complication of hemophilia. A Central European J Med 2007, 2:539-542.

5. Sibulesky L, Ridlen M, Pricolo VE: Hemobilia due to cystic artery pseudoaneurysm. Am J Surg 2006, 191:797-8.

6. Wu TC, Liu TJ, Ho YJ: Pseudoaneurysm of the cystic artery with upper gastrointestinal hemorrhage. Acta Chir Scand 1988, 154:151-2.

7. Del Gadillo X, Berney T, Perrot M, et al: Successful treatment of a pseudoaneurysm of the cystic artery with microcoil embolisation. J Vasc Interv Radiol 1999, 10:789-92

doi:10.1186/1749-7922-5-8

Cite this article as: Ben-Ishay et al.: Gallbladder ulcer erosion into the cystic artery: a rare cause of upper gastro-intestinal bleeding Case report. World Journal of Emergency Surgery 2010 5:8

\section{Submit your next manuscript to BioMed Central} and take full advantage of:

- Convenient online submission

- Thorough peer review

- No space constraints or color figure charges

- Immediate publication on acceptance

- Inclusion in PubMed, CAS, Scopus and Google Scholar

- Research which is freely available for redistribution

Submit your manuscript at www.biomedcentral.com/submit
Ciomed Central 